\title{
Pengaruh Keselamatan Dan Kesehatan Kerja Terhadap Kinerja Pegawai
}

\author{
${ }^{1}$ Elvizal Rangkuti, ${ }^{2}$ Fauzi Ramadhan Singarimbun, ${ }^{3}$ Superizal, ${ }^{4}$ Mas Pratama \\ ${ }^{1-4}$ Program Magister Manajemen, Fakultas Ekonomi, Universitas Islam Sumatera Utara
}

\section{Article history}

Received: 18 Nov 2020

Revised: 30 Dec 2020

Accepted: 7 Jan 2021

\section{*Corresponding Author: Elvizal Rangkuti, Program Studi Magister Manajemen, Fakultas Ekonomi, \\ Universitas Islam Sumatera Utara \\ Email: \\ Elvizalrangkuti13@gmail. $\underline{\text { com }}$}

\section{PENDAHULUAN}

Dalam menjalankan suatu bisnis perusahaan membutuhkan berbagai sumber daya, seperti modal. Perusahaan juga membutuhkan sumber daya manusia berupa para pegawai. Sumber daya manusialah yang paling penting dan sangat menentukan, karena tanpa sumber daya manusia yang bagus, maka perusahaan itu tidak akan berjalan dengan baik pula. Peranan sumber daya manusia dalam sebuah perusahaan sangat banyak diperbincangkan, sehingga berbagai cara diusahakan untuk mengembangkan kinerja dan meningkatkan taraf hidup manusia. Karena kinerja adalah hasil kerja secara kuanitas dan kualitas yang dicapai oleh seorang pegawai dalam melaksanakan tugas kerjanya (Mangkunegara, 2011). Tingginya ketidakhadiran pegawai yang dapat dilihat pada daftar absensi, hal ini diduga disebabkan adanya tekanan kerja yang disebabkan oleh lingkungan kerja, kepemimpinan yang kurang memberi motivasi, dan menuntut pegawai supaya memenuhi target yang ditentukan perusahaan.

Peranan manajemen perusahaan dalam mengarahkan, membimbing serta menciptakan iklim industry yang sehat kepada perusahaan adalah untuk menciptakan struktur ekonomi yang lebih kuat dan seimbang. Hal ini sejalan dengan pengertian manajemen personalia itu sendiri yaitu seni dan ilmu memperoleh, memajukan dan memanfaatkan tenaga kerja sedemikian rupa sehingga tujuan organisasi dapat direalisir secara berdaya guna dan berhasil guna dan adanya kegairahan kerja dari para tenaga kerja (Manullang 2011).

Seiring perkembangan ilmu pengetahuan dan teknologi canggih serta munculnya inovasi-inovasi baru telah mendorong perusahaan untuk meningkatkan pengetahuan dan keterampilan sumber daya manusianya, agar dapat menghasilkan produk yang berkualitas tinggi. Sumber daya manusia sebagai pegawai tidak lepas dari masalah yang berkaitan dengan keselamatan dan kesehan kerja sewaktu bekerja Keselamatan dan kesehatan kerja 
berfungsi untuk menciptakan suasana dan lingkungan kerja yang menjamin kesehatan dan keselamatan pegawai agar tugas pekerjaan di wilayah kerja perusahaan dapat berjalan lancer (Prawirosentono, 2012). Dengan menjamin keselamatan dan kesehatan kerja dapat menumbuhkan semangat kerja pada pegawai. Sebagaimana menurut Mondy dan Noe dalam Panggabean (2012) bahwa manajemen keselamatan kerja dibutuhkan untuk perlindungan pegawai dari kecelakaan di tempat kerja sedangkan kesehatan merujuk kepada kebebasan pegawai dari penyakit secara fisik maupun mental.

Menurut Astuti (2011:72), keselamatan dan kesehatan kerja (K3) adalah suatu program yang dibuat oleh pemerintah yang harus dipatuhi dan dilaksanakan pengusaha maupun pekerja sebagai upaya mencegah timbulnya kecelakaan akibat kerja dan penyakit akibat kerja dengan cara mengenali hal yang berpotensi menimbulkan kecelakaan dan penyakit akibat. Tujuannya adalah untuk menciptakan tempat kerja yang nyaman, dan sehat sehingga dapat menekan serendah mungkin resiko kecelakaan dan penyakit. Perhatian terhadap kesehatan pekerjaan pada mulanya lebih menekankan pada masalah keselamatan kerja yaitu perlindungan pekerjaan dari kerugian atau luka yang disebabkan oleh kecelakaan berkaitan dengan kerja. Kemudian seiring dengan perkembangan industri, perusahaan mulai memperhatikan kesehatan pekerja dalam arti luas yaitu terbebasnya pekerjaan dari kesakitan fisik maupun psikis (Bangun, 2012). Oleh karena itu, keselamatan kerja sangat berpengaruh terhadap kinerja kerja pegawai.

\section{METODE PENELITIAN}

Teknik analisis data yang digunakan dalam penelitian ini adalah analisis data kuantitatif, yaitu menguji dan menganalisis data dengan perhitungan angka-angka dan kemudian menarik kesimpulan dari pengujian. Pengumpulan data menggunakan metode kuantitatif melalui kuesioner yang disebar ke responden atau pegawai di Kantor Navigasi Kelas I Belawan berjumlah 63 orang. Melalui uji sampel dianggap cukup untuk menjawab masalah yang ingin di teliti terkait pengaruh keselamatan dan kesehatan terhadap karyawan. Menurut Supranto (2011) populasi adalah kumpulan seluruh elemen yang sejenis akan tetapi dapat dibedakan satu sama lain. Perbedaan-perbedaan itu disebabkan karena adanya nilai karateristik yang berlainan. Dalam hal ini mengambil populasi dari seluruh pegawai Kantor Navigasi Kelas I Belawan yang berjumlah 171 orang pegawai. Penentuan ukuran sampel dalam penelitian ini dilakukan menggunakan rumus Slovin (Sugiyono, 2010).

\section{Teknik Pengumpulan Data}

Metode pengumpulan data dengan membuat daftar pertanyaan dalam bentuk angket yang ditunjukkan kepada para pegawai atau responden pada Kantor Navigasi Kelas I Belawan. Dalam hal ini memberikan daftar pertanyaan kepada responden untuk memperoleh data yang berhubungan variabel yang diteliti. Melakukan Tanya jawab dengan pimpinan perusahaan, kepala-kepala bagian dan para pegawai yang bersangkutan untuk memberikan data atau informasi yang ada hubungannya dengan penelitian ini. Selain itu melalui studi dokumentasi yaitu mempelajari data-data yang ada dalam perusahaan dan berhubungan dengan penelitian, seperti sejarah perusahaan, struktur organisasi dan sumber data jumlah pegawai dan lainnya yang berhubungan dengan penelitian ini. 


\section{Teknik Analisis Data}

Pada bagian ini akan dibahas mengenai bentuk sebaran jawaban responden terhadap keseluruhan konsep yang diukur. Dari sebaran jawaban responden tersebut, selanjutnya akan diperoleh sebuah kecenderungan dari seluruh jawaban yang ada. Untuk mendapat kecenderungan jawaban responden terhadap masing-masing variabel, akan didasarkan pada nilai skor rata-rata (indeks) yang dikategorikan ke dalam tentang skor berdasarkan perhitungan three box method berikut ini. Proses ini melalui beberapa tahapan yaitu scoring dan tabulating.

\section{Uji Validitas Data}

Uji validitas dilakukan untuk me-tes, apakah kuesioner yang akan kita ajukan kepada responden sudah sahih atau valid yang bersumber dari jawaban-jawaban responden dengan skala likert. Untuk men-tes ini diperlukan sampel minimal 30 responden. Jika ada jawaban yang tidak valid maka butir pertanyaan/pernyataan tidak boleh dimasukkan dalam pengolahan data berikutnya seperti : Pengelolaan Data Regresi Linear baik Sederhana maupun Berganda, Kolerasi Sederhana/ Berganda, SEM, Analisis Jalur. Untuk menguji validitas ini digunakan pengolahan data melalui Rank Spearman, nilai suatu kuesioner dinyatakan valid biasanya ditetapkan dengan angka korelasi 0.30 (Azwar, 2013).

\section{Uji Reliabilitas}

Uji reliabilitas dilakukan untuk me-tes, apakah kuesioner yang akan atau kita ajukan kepada responden sudah reiabel atau andal yang bersumber dari jawaban-jawaban responden dengan skala likert. Jika ada jawaban yang tidak reliabel maka butir pertanyaan/ pernyataan tidak boleh dimasukkan dalam pengelolahan data berikutnya. Nilai suatu kuesioner dinyatakan reliabel biasanya ditetapkan dengan angka alpha 0.70-0.80 cukup baik untuk tujuan penelitian dasar menurut Kaplan-Saccuzz (2013).

\section{HASIL DAN PEMBAHASAN}

Kuesioner yang disebar ke responden atau pegawai di Kantor Navigasi Kelas I Belawan berjumlah 63 orang. Penjelasan responden atas indikator-indikator variabel keselamatan dan kesehatan kerja di Kantor Navigasi Kelas I Belawan disajikan berikut ini:

Tabel 1. Penjelasan Responden Atas Variabel Keselamatan dan Kesehatan Kerja ( $\left.\mathrm{X}_{1}\right)$

\begin{tabular}{|c|c|c|c|c|c|c|c|c|c|c|c|c|}
\hline \multirow{2}{*}{ No } & \multicolumn{9}{|c|}{ ALTERNATIF JAWABAN } \\
\cline { 2 - 15 } & \multicolumn{2}{|c|}{ SS } & \multicolumn{2}{|c|}{ S } & \multicolumn{2}{|c|}{ KS } & \multicolumn{2}{|c|}{ TS } & \multicolumn{2}{|c|}{ STS } & \multicolumn{2}{|c|}{ Jumlah } \\
\cline { 2 - 15 } & F & $\%$ & F & $\%$ & F & $\%$ & F & $\%$ & F & $\%$ & F & $\%$ \\
\hline 1 & 33 & $52,4 \%$ & 24 & $38,1 \%$ & 6 & $9,5 \%$ & 0 & $0,0 \%$ & 0 & $0,0 \%$ & 63 & $100 \%$ \\
\hline 2 & 29 & $46,0 \%$ & 28 & $44,4 \%$ & 6 & $9,5 \%$ & 0 & $0,0 \%$ & 0 & $0,0 \%$ & 63 & $100 \%$ \\
\hline 3 & 21 & $33,3 \%$ & 34 & $54,0 \%$ & 8 & $12,7 \%$ & 0 & $0,0 \%$ & 0 & $0,0 \%$ & 63 & $100 \%$ \\
\hline 4 & 15 & $23,8 \%$ & 42 & $66,7 \%$ & 6 & $9,5 \%$ & 0 & $0,0 \%$ & 0 & $0,0 \%$ & 63 & $100 \%$ \\
\hline
\end{tabular}




\begin{tabular}{|c|c|c|c|c|c|c|c|c|c|c|c|c|}
5 & 24 & $38,1 \%$ & 33 & $52,4 \%$ & 6 & $9,5 \%$ & 0 & $0,0 \%$ & 0 & $0,0 \%$ & 63 & $100 \%$ \\
\hline Rata2 & 24 & $38,7 \%$ & 32 & $51,1 \%$ & 6 & $10,2 \%$ & 0 & $0,0 \%$ & 0 & $0,0 \%$ & 63 & $100 \%$ \\
\hline
\end{tabular}

Sumber: Hasil Penelitian 2020

Dari Tabel 1 di atas dapat dijelaskan bahwa:

1) Jawaban responden pertanyaan No.1: Perusahaan selalu menyediakan atribut pelindung kerja sesuai standar nasional agar terhindar dari kecelekaan kerja. Responden yang menjawab sangat setuju sebesar $52,4 \%$, setuju sebesar $38,1 \%$, kurang setuju sebesar $9,5 \%$.

2) Jawaban responden pertanyaan No.2: Perusahaan memberikan fasilitas ruang kerja yang aman kepada pegawai. Responden yang menjawab sangat setuju sebesar $46,0 \%$, setuju $44,4 \%$, kurang setuju sebesar 9,5\%.

3) Jawaban responden pertanyaan No.3: Pegawai selalu menggunakan atribut atau peralatan kerja yang berstandar nasional dalam bekerja. Responden yang menjawab sangat setuju sebesar 33,3\%, setuju sebesar 54,0\%, dan kurang setuju sebesar 12,7\%.

4) Jawaban responden pertanyaan No.4: Perusahaan memberikan fasilitas ruang kerja yang sehat dan bersih kepada pegawai sehingga merasa nyaman dalam bekerja. Responden yang menjawab sangat setuju sebesar $23,8 \%$, yang menjawab setuju sebesar $66,7 \%$, kurang setuju sebesar $9,5 \%$.

5) Jawaban responden pertanyaan No.5: Fasilitas penerangan di ruang kerja pegawai sudah baik dan sesuai aturan. Responden yang menjawab sangat setuju sebesar $38,1 \%$, yang menjawab setuju sebesar 52,4\%, kurang setuju sebesar 9,5\%.

Secara rata-rata dapat dilihat bahwa yang terbesar jawaban responden adalah $51,1 \%$ menyatakan setuju. Dengan demikian dapat diketahui bahwa keselamatan dan kesehatan kerja di Kantor Navigasi Kelas I Belawan adalah baik, sesuai dengan jawaban sebagian besar responden. Penjelasan responden atas indikator-indikator variabel kinerja (Y) di Kantor Navigasi Kelas I Belawan, disajikan pada Tabel berikut ini:

Tabel 2. Penjelasan Responden Atas Variabel Kinerja (Y)

\begin{tabular}{|c|c|c|c|c|c|c|c|c|c|c|c|c|}
\hline \multirow{2}{*}{ No } & \multicolumn{9}{|c|}{ ALTERNATIF JAWABAN } \\
\cline { 2 - 14 } & \multicolumn{2}{|c|}{ SS } & \multicolumn{2}{|c|}{ S } & \multicolumn{2}{|c|}{ KS } & \multicolumn{2}{|c|}{ TS } & \multicolumn{2}{|c|}{ STS } & \multicolumn{2}{|c|}{ Jumlah } \\
\cline { 2 - 14 } & $\mathbf{F}$ & $\%$ & $\mathbf{F}$ & $\%$ & $\mathbf{F}$ & $\%$ & $\mathbf{F}$ & $\%$ & $\mathbf{F}$ & $\%$ & F & $\%$ \\
\hline 1 & 34 & $54,0 \%$ & 29 & $46,0 \%$ & 0 & $0,0 \%$ & 0 & $0,0 \%$ & 0 & $0,0 \%$ & 63 & $100 \%$ \\
\hline 2 & 15 & $23,8 \%$ & 47 & $74,6 \%$ & 1 & $1,6 \%$ & 0 & $0,0 \%$ & 0 & $0,0 \%$ & 63 & $100 \%$ \\
\hline 3 & 11 & $17,5 \%$ & 36 & $57,1 \%$ & 16 & $25,4 \%$ & 0 & $0,0 \%$ & 0 & $0,0 \%$ & 63 & $100 \%$ \\
\hline 4 & 23 & $36,5 \%$ & 27 & $42,9 \%$ & 13 & $20,6 \%$ & 0 & $0,0 \%$ & 0 & $0,0 \%$ & 63 & $100 \%$ \\
\hline 5 & 13 & $20,6 \%$ & 40 & $63,5 \%$ & 10 & $15,9 \%$ & 0 & $0,0 \%$ & 0 & $0,0 \%$ & 63 & $100 \%$ \\
\hline 6 & 15 & $23,8 \%$ & 48 & $76,2 \%$ & 0 & $0,0 \%$ & 0 & $0,0 \%$ & 0 & $0,0 \%$ & 63 & $100 \%$ \\
\hline Rata2 & 19 & $29,4 \%$ & 38 & $60,1 \%$ & 7 & $10,6 \%$ & 0 & $0,0 \%$ & 0 & $0,0 \%$ & 63 & $100 \%$ \\
\hline
\end{tabular}


Sumber: Hasil Penelitian 2020

Dari Tabel 2 diatas dapat dijelaskan bahwa:

1) Jawaban responden pertanyaan No.1: Kuantitas hasil kerja pegawai selama ini dapat dikategorikan baik. Responden yang menjawab sangat setuju sebesar 54,0\%, responden yang menjawab setuju sebesar $46,0 \%$.

2) Jawaban responden pertanyaan No.2: Kualitas hasil kerja pegawai selama ini dapat dikategorikan baik. Responden yang menjawab sangat setuju sebesar 23,8\%, responden yang menjawab setuju sebesar 74,6\%, responden yang menjawab kurang setuju sebesar $1,6 \%$.

3) Jawaban responden pertanyaan No.3: Tingkat efisiensi kerja para pegawai dapat dikategorikan baik. Responden yang menjawab sangat setuju sebesar 17,5\%, responden yang menjawab setuju sebesar $57,1 \%$, responden yang menjawab kurang setuju sebesar $25,4 \%$.

4) Jawaban responden pertanyaan No.4: Proses pelayanan, administrasi dan informasi pegawai terhadap yang membutuhkan sudah baik. Responden yang menjawab sangat setuju sebesar $36,5 \%$, responden yang menjawab setuju sebesar $42,9 \%$, responden yang menjawab kurang setuju sebesar 20,6\%.

5) Jawaban responden pertanyaan No.5: Ketepatan pegawai dalam melaksanakan suatu pekerjaan sudah baik. Responden yang menjawab sangat setuju sebesar 20,6\%, responden yang menjawab setuju sebesar $63,5 \%$, responden yang menjawab kurang setuju sebesar $15,9 \%$.

6) Jawaban responden pertanyaan No.6: Pengetahuan pegawai berkaitan dengan pekerjaan utamanya sudah baik. Responden yang menjawab sangat setuju sebesar 23,8\%, responden yang menjawab setuju sebesar $76,2 \%$.

Secara rata-rata dapat dilihat bahwa yang terbesar jawaban responden adalah $60,1 \%$ menyatakan setuju. Dengan demikian dapat diketahui bahwa kinerja pegawai di Kantor Navigasi Kelas I Belawan adalah baik, sesuai dengan jawaban sebagian besar responden.

\section{Uji Validitas}

Uji validitas dilakukan dengan menghitung korelasi antar skor masing-masing butir pernyataan dan total skor. Dari tabel 5.7 dibawah ini terlihat bahwa kolerasi semua item untuk keselamatan dan kesehatan kerja $\left(\mathrm{X}_{1}\right)$, menunjukan hasil yang signifikan yaitu nilai pearson correlation $>0,248$ sehingga dapat disimpulkan semua butir pernyataan keselamatan dan kesehatan kerja $\left(\mathrm{X}_{1}\right)$ adalah valid.

\section{Uji Reliabilitas}

Untuk menguji reliabilitas yang paling sering digunakan kebanyakan peneliti dengan menggunakan Crobach Alpha. Nilai suatu kuesioner dinyatakan reliabel biasanya ditetapkan dengan angka alpha 0.70-0.80 cukup baik untuk tujuan penelitian dasar menurut KaplanSaccuzz (2013).

\section{Uji Asumsi Klasik}




\section{Uji Normalitas Data}

Dalam penelitian ini pengujian normalitas dideteksi melalui analisa grafik P-P Plot.yang dihasilkan melalui SPSS. Berdasarkan analisis penelitian terlihat bahwa grafik histogram memberikan pola distribusi normal tidak berpola distribusi melenceng (skwewness) ke kiri atau ke kanan, maka model regresi memenuhi asumsi normalitas.

\section{Uji Multikolinearitas}

Metode untuk menguji ada tidaknya multikolinearitas dapat dilihat Tolerance Value dan Inflation Factor (VIF). Batas tolerance value adalah 0,10 atau nilai VIF adalah 10. Jika tolerance value $>0,10$ dan VIF $<10$ maka tidak terjadi multikolinearitas dan sebaliknya jika tolerance value $<0,10$ dan VIF $>10$ maka terjadi multikoleniaritas. Berdasarkan hasil perhitungan nilai variance inflaction factor (VIF) menunjukkan bahwa tidak ada satu variabel independen yang memiliki nilai VIF lebih dari 10. Jadi dapat disimpulkan bahwa tidak ada multikolinieritas antar variabel independen dalam model regresi.

\section{Uji Heteroskedastisitas}

Uji heteroskedastisitas dilakukan untuk mengetahui apakah dalam sebuah model regresi terjadi ketidaksamaan varians dari residual suatu pengamatan ke pengamatan lain. Jika varians dari residual suatu pengamatan ke pengamatan lain tetap disebut heteroskedastisitas. Menganalisis data dalam pengujian asumsi klasik ini, peneliti menggunakan Program Statistical Product and Service Solution (SPSS Versi 20.) Dengan demikian dapat dikatakan bahwa regresi tidak mengalami gangguan heteroskedastisitas pada model regresi sehingga model regresi layak dipakai untuk mengetahui kinerja (Y) berdasarkan variabel bebasnya.

\section{Uji Autokorelasi}

Uji autokorelasi digunakan untuk melihat hubungan antara variabel bebas memiliki hubungan sama kuat atau tidak, dimana untuk melihat hubungan atau tidak hubungan secara autokorelasi dapat dilihat dengan Uji Durbin-Watson (DW test). Uji Durbin-Watson hanya digunakan untuk autokorelasi tingkat satu (first order autocorrelation) dan mensyaratkan adanya intercept (kostanta) dalam model regresi dan tidak ada variabel lain diantara variabel independent. Berdasarkan hasil yang diperoleh nilai Durbin-Watson sebesar 1.860. Nilai Durbin-Watson menurut tabel dengan $\mathrm{n}=63$ responden dan $\mathrm{k}=3$ (dalam hal ini adalah jumlah variabel bebas) didapat angka $\mathrm{dl}=1.494 \mathrm{dan} \mathrm{du}=1.693$. Oleh karena itu nilai DW hitung > du $(1.860>1.688)$, maka dapat disimpulkan bahwa tidak terdapat autokorelasi dalam model regresi maka model layak untuk digunakan.

\section{KESIMPULAN}

Berdasarkan hasil analisis yang telah dibahas, maka ditarik kesimpulan bahwa keselamatan dan kesehatan kerja berpengaruh positif dan signifikan terhadap kinerja pegawai di Kantor Navigasi Kelas I Belawan dengan thitung $>t_{\text {tabel }}(4.098>1.998)$ dan nilai koefisien regresi sebesar 0.436 atau $43,6 \%$.

\section{DAFTAR PUSTAKA}

Astuti, Okky Suli. 2011. Pengaruh Kesehatan dan Keselamatan Kerja Terhadap Produktifitas Kerja Karyawan Bagian Produksi PT. Indmira Citra Tani Nusantara di Yogyakarta.Skripsi Universitas Pembangunan Nasional "Veteran". 
Azwar. Saifuddin. 2013. Metode Penelitian. Yogyakarta: Pustaka Pelajar.

Bangun, Wilson. 2012. “Manajemen Sumber Daya Manusia”. Jakarta: Erlangga.

Kaplan, Robert M dan Saccuzo, Dennis P. 2013. Reliabilitas dan Validitas. Edisi 3.Terjemahan: Handoko. Yogyakarta: Pustaka Pelajar

Mangkunegara, Anwar Prabu. 2011, Perencanaan dan Pengembangan Manajemen Sumber Daya Manusia, Pen. PT Refika Aditama

Manullang, Marihot. 2006. Manajemen Personalia. Gadjah Mada University Press, Yogakarta

Panggabean, Mutiara Sibarani. 2012. Manajemen Sumber Daya Manusia. Jakarta: Ghalia Indonesia.

Prawirosentono, Suyadi. 2012. Manajemen Sumber Daya Manusia: Kebijakan Kinerja Karyawan. Edisi 1. Cetakan Kedelapan. BPFE. Yogyakarta

Sugiyono. 2010. Metode Penelitian Pendidikan Pendekatan Kuantitatif, kualitatif, dan R\&D. Bandung: Alfabeta

Supranto. 2011. Metode Riset : Aplikasinya dalam Pemasaran. Jakarta: Rineka Cipta 